\title{
利用激光雷达数据估算韩国森林有效植被面积 指数
}

\author{
KWAK Doo-Ahn ${ }^{(1)}$, LEE Woo-Kyun ${ }^{\left(\mathbb{1}^{*}\right.}$, KAFATOS Menas ${ }^{(2)}$, CHO Hyun-Kook ${ }^{(3)}$ \\ (1) Department of Environmental Science and Ecological Engineering, Korea University, Seoul 136-713, Korea; \\ (2) Center of Excellence in Earth Observing, Schmid College of Science, Chapman University, Orange, CA 92866, USA; \\ (3) Division of Forest Resources Information, Korea Forest Research Institute, Seoul 136-012, Korea \\ * 联系人, E-mail: leewk@korea.ac.kr
}

收稿日期: 2010-02-09; 接受日期: 2010-04-03

摘要雷达系统能够同时探测森林的水平结构和垂直结构, 结合地面控制点还可以高精度地描绘森林中的树 干、树冠及林下植被. 基于此理念, 通过计算雷达激光束被拦截的比例估算红松(Pinus koraiensis)、日本落叶松 (Larix leptolepis)和栋类( Quercus sp.)的有效植被面积指数 $\left(\mathrm{PAI}_{e}\right)$. 从冠层表面或冠层内部反射的雷达数据中利用 $k$-均值聚类方法提取林隙分数 $\left(G_{\mathrm{LIDAR}}\right)$, 根据比尔-朗伯吸收定律和 $G_{\mathrm{LIDAR}}$ 计算 $\mathrm{PAI}_{e}$. 结果显示, 利用雷达数据推 算的红松、日本落叶松和栋类的 $\mathrm{PAI}_{e}$ 与实际测量的 $\mathrm{PAI}_{e}$ 之间的相关系数分别为 $0.82,0.64$ 和 0.59 . 不同树种之 间雷达测量值与实测值之间相关性的差异, 主要来自于叶片与枝条数量的不同. 如果没有树叶, 激光雷达的脉 冲只能由枝条反射, 然而枝条的大小往往小于激光雷达的分辨率 $(1 \mathrm{~m})$, 所以与长满树叶的枝条相比, 光秃的枝 条反射雷达脉冲的几率非常小. 因此, 若在春季末期树叶出现后进行此类研究, 估算的准确度将有所提高.

\section{关键词叶面积指数 植被面积指数 激光雷达 $k$-均值聚类 林隙 比尔-朗伯吸收定律}

全文见: Kwak D A, Lee W K, Kafatos M, et al. Estimation of effective plant area index for South Korean forests using LiDAR system. Sci China Life Sci, 2010, 53: 898 - 908, doi: 10.1007/s11427-010-4019-z 